\title{
Pengaruh Kepemimpinan Demokratis Kepala Ruang Rawat Inap terhadap Kepuasan Kerja Perawat di Rumah Sakit Umum Aro Pekalongan
}

\author{
Broto Rahardjo*, Chriswardani Suryawati**, Farid Agushyana** \\ *Alumni Magister Ilmu Kesehatan Masyarakat Universitas Diponegoro, Semarang \\ **Fakultas Kesehatan Masyarakat, Universitas Diponegoro, Semarang
}

Email: brotodr@gmail.com

\section{ABSTRACT}

Leadership styles that are less suitable can reduce employee motivation, performance and job satisfaction. 4 out of 10 nurses in the inpatient room of Aro Pekalongan General Hospital felt dissatisfied with the leadership of the head of the inpatient room. Therefore a study was conducted to analyze the influence of the democratic leadership style of the inpatient head on the job satisfaction of nurses in Aro Pekalongan General Hospital.

The study design was cross sectional with an observational quantitative approach. The research subjects were 32 nurses in the inpatient room of Aro General Hospital who were selected by the total sampling method. Data was collected by questionnaire. Processing and analysis of data using multiple logistic regression analysis.

The results showed the variables of democratic leadership style related to nurse job satisfaction in Aro Pekalongan Hospital were delegation of responsibility variables $(p=0.005)$ and headroom decision-making variables $(p=0.034)$, while other variables not related to nurse job satisfaction were variable of headroom activity $(p=0.077)$ and empathy variable $(p=0.075)$. The variable delegation of tagging answers to the head of the room has a 19 times better effect on influencing nurse job satisfaction compared to the head of the room with poor delegation of responsibilities $(p=0.011 \operatorname{Exp}(B)=$ 19.826).

It is recommended for management for periodic monitoring and evaluation, the selection of the head of the room is based on the length of work, competence and experience of advice for the head of the room to improve effective communication and hold regular meetings with nurses in the inpatient room of Aro Pekalongan General Hospital.

Keywords: Democratic Leadership, Nurse, Head Room

\section{PENDAHULUAN}

Kepemimpinan dalam keperawatan adalah proses mempengaruhi staff untuk dapat meningkatkan kepercayaan dan kepatuhan sehingga timbul kesadaran dan kemauan staff untuk dapat bekerja sesuai dengan tujuan bersama secara efektif dan efisien. ${ }^{1}$

Kepemimpinan merupakan salah satu faktor yang dapat mempengaruhi kepuasan karyawan dan berdampak pada kinerja karyawan pada suatu institusi. Berdasarkan hasil penelitian ditemukan bahwa kepemimpinan merupakan aspek terbesar yang dapat mempengaruhi kepuasan kerja karyawan. ${ }^{2}$ 
Hasil penelitian menunjukkan 10,1\% perawat di rumah sakit swasta Jakarta dan $13,79 \%$ perawat di ruang rawat inap RS Provinsi Sakaeo menunjukkan bahwa tidak puas dengan gaya kepemimpinan kepala ruang. ${ }^{3} 4$

Berdasarkan hasil studi pendahuluan dengan melakukan wawancara dengan 4 dari 10 perawat di ruang rawat inap RSU Aro Pekalongan tidak puas dengan gaya kepemimpinan kepala ruang dimana kepala ruang tidak mau menerima pendapat, kepala ruang cenderung memerintah, acuh terhadap permasalahan bawahan dan kurangnya kesempatan para perawat untuk mendapatkan pelatihan.

Penelitian ini bertujuan untuk mengetahui pengaruh gaya kepemimpinan demokratis kepala ruang rawat inap terhadap kepuasan kerja perawat di RSU Aro Kota Pekalongan.

Gaya kepemimpinan Demokratis merupakan gaya dimana pemimpin memahami dan menghargai sifat dan keinginan staff, mampu memotivasi staff, membuat rencana monitoring dan evaluasi serta terbuka terhadap informasi. ${ }^{2}$ Gaya kepemimpinan demokratis merupakan gaya kepemimpinan yang paling baik yang dapat diterapkan pada suatu organisasi karena pemimpin dapat mempengaruhi produktivitas dan kepuasan kelompok. ${ }^{1}$

\section{METODE PENELITIAN}

Penelitian ini merupakan penelitian kuantitatif dengan pendekatan waktu potong lintang (cross sectional). Pengumpulan data primer menggunakan kuesioner terstruktur, terhadap variabel pendelegasian tanggung jawab, keaktifan kepala ruang, pengambilan keputusan, empati dan kepuasan kerja perawat. Sampel pada penelitian ini sebanyak 32 orang perawat yang melaksanakan tugas dan fungsi keperawatan di RSU Aro Pekalongan, pengambilan sampel dilakukan dengan metode Total sampling, Analisis data penelitian dengan menggunakan korelasi chi square.

\section{Hasil Penelitian}

Data hasil penelitian menunjukkan bahwa sebanyak $68,8 \%$ responden berumur 21-25 tahun, $90,6 \%$ berjenis kelamin perempuan, $56,3 \%$ responden memiliki tingkat pendidikan D3 Keperawatan dan 50\% responden memiliki masa kerja 1-5 tahun.

Pendelegasian tanggung jawab kepala ruang sebagian besar responden mempersepsikan baik (53\%) karena kepala ruang menjadikan beban kerja sebagai tanggung jawab bersama dan kepala ruang selalu memberikan tugas dan tanggung jawab pada perawat.

Keaktifan kepala ruang sebagian responden mempersepsikan baik dan sebagian lainnya mempersepsikan kurang (50\%). Kurangnya keaktifan kepala ruang dikarenakan kepala ruang kurang terbuka dan proses komunikasi masih satu arah, serta belum bisa memberi petunjuk pada perawat yang memerlukan bantuan.

Pengambilan keputusan kepala ruang sebagian besar responden mempersepsikan baik (53\%), dan sebagian responden mempersepsikan kepala ruang tidak baik dalam mengambil keputusan karena jarang memberi kesempatan perawat dalam mengemukakan pendapat.

Empati kepala ruang sebagian besar responden sudah mempersepsikan baik $(56 \%)$ karena kepala ruang selalu menciptakan suasana kekeluargaan yang menyenangkan dan dapat bersifat ramah.

Kepuasan perawat di ruang rawat inap RSU Aro Pekalongan sebagian sudah merasa puas dan sebagian lainnya merasa tidak puas. Ketidakpuasan perawat dikarenakan faktor kenaikan gaji/promosi belum ditangani dengan adil dan besaran gaji belum sesuai dengan kontribusi sebagai perawat.

Tabel 1 Hubungan Pendelegasian Tanggung Jawab dengan Kepuasan

\begin{tabular}{ccccc}
\hline \multirow{2}{*}{ Pendelegasian } & \multicolumn{3}{c}{ Kepuasan } \\
\cline { 2 - 4 } Tanggung Jawab & \multicolumn{2}{c}{ Puas } & \multicolumn{2}{c}{ Tidak Puas } \\
\cline { 2 - 4 } & f & $\%$ & $\mathrm{f}$ & $\%$ \\
\hline
\end{tabular}




\begin{tabular}{lcccc}
\hline Baik & 13 & 40,6 & 4 & 12,5 \\
\hline Kurang & 3 & 9,4 & 12 & 37,5 \\
\hline \multicolumn{1}{c}{${ }^{*} p=0,005$} & & & &
\end{tabular}

Hasil uji hubungan chi square menunjukkan terdapat hubungan antara variabel pendelegasian tanggung jawab kepala ruang dengan kepuasan perawat di ruang rawat inap RSU Aro Pekalongan $(\mathrm{p}<0,05)$.

$\begin{array}{lrr}\text { Pendelegasian tanggung jawab } & \text { jangsi } \\ \text { merupakan salah satu fungsi } & \text { tersebut } \\ \text { pengorganisasian dimana fungsian salah satu fungsi penting dalam } \\ \text { merupakan sala } \\ \text { manajemen. Pelaksanaan fungsi }\end{array}$
pengorganisasian di ruang rawat inap dapat mempengaruhi kualitas pelayanan keperawatan yang diberikan, karena dalam fungsi tersebut terdapat kegiatan pembagian kerja, pendelegasian tugas dan tanggung jawab, koordinasi kerja dan manajemen waktu yang dilakukan oleh seorang kepala ruang. ${ }^{5,6}$

Pendelegasian tanggung jawab kepala ruang Pekalongan berhubungan dengan kepuasan perawat di ruang rawat inap di RSU Aro Pekalongan. Hal tersebut dikarenakan tanggung jawab merupakan hal yang diinginkan oleh karyawan, karena keinginan tersebut merupakan suatu bentuk dari kebutuhan karyawan untuk berprestasi. Pendelegasian tanggung jawab kepada orang yang salah akan berakibat pada keputusan yang diambil cenderung tidak tepat dan salah serta akan berdampak pada karyawan yang merasa tidak dihargai di organisasinya. Karyawan yang merasa dihargai dan dibutuhkan di dalam organisasinya maka kepuasan kerjanya akan meningkat dibandingkan dengan karyawan yang merasa dirinya tidak dihargai atau tidak dibutuhkan. ${ }^{7}$

Pendelegasian tanggung jawab sangat perlu dilakukan oleh pimpinan dalam suatu organisasi, hal tersebut bertujuan agar pimpinan dapat mengembangkan bawahan serta agar dapat tercapainya fungsi-fungsi dalam organisasi secara efisien. Pendelegasian tanggung jawab yang dilakukan oleh kepala ruang rawat inap RSU ARO kepada perawat di ruang rawat inap tersebut adalah dengan mengkoordinasi perawat dalam kegiatan pelayanan rawat inap diantaranya adalah dengan melakukan pembagian tugas bersama perawat, mengikutsertakan perawat dalam pertemuan ilmiah, serta memberi tanggung jawab kepada masingmasing perawat terkait kelengkapan data rekam medik serta pelaksanaan inventaris ruangan.

Penelitian ini sesuai dengan teori yang dikemukakan oleh Herzberg yang menyebutkan bahwa salah satu faktor yang mempengaruhi kepuasan kerja seseorang adalah faktor pemuas yang meliputi prestasi, pengakuan, tanggung jawab, pekerjaan itu sendiri dan kemungkinan berkembang. ${ }^{8}$ Serta sesuai dengan penelitian yang dilakukan oleh Johanes dimana faktor kesejahteraan yang terdiri dari faktor tanggung jawab berpengaruh terhadap kepuasan kerja karyawan. ${ }^{5}$

Tabel 2 Hubungan Keaktifan Pimpinan dengan Kepuasan

\begin{tabular}{|c|c|c|c|c|}
\hline \multirow{3}{*}{$\begin{array}{l}\text { Keaktifan } \\
\text { Pimpinan }\end{array}$} & \multicolumn{4}{|c|}{ Kepuasan } \\
\hline & \multicolumn{2}{|c|}{ Puas } & \multicolumn{2}{|c|}{ Tidak Puas } \\
\hline & $\mathrm{f}$ & $\%$ & $f$ & $\%$ \\
\hline Baik & 11 & 34,4 & 5 & 15,6 \\
\hline Kurang & 5 & 15,6 & 11 & 34,4 \\
\hline
\end{tabular}

Hasil uji hubungan chi square menunjukkan tidak terdapat hubungan antara variabel keaktifan kepala ruang dengan kepuasan perawat di ruang rawat inap RSU Aro Pekalongan ( $p>0,05)$.

Keaktifan kepala ruang tidak berhubungan dengan kepuasan perawat di rawat inap di RSU Aro Pekalongan.

Pengarahan, pengawasan dan bimbingan kepala ruang berdampak penting bagi perawat dikarenakan dengan adanya arahan dan bimbingan kepala ruang maka perawat akan merasa mendapatkan reward dari adanya perhatian yang diberikan oleh kepala ruang 
terhadap perawat sehingga perhatian tersebuat akan dirasakan menjadi sebuah kepuasan tersendiri dalam proses pencapaian tujuan kerja. ${ }^{9}$

Salah satu kunci suksesnya gaya kepemimpinan demokratis adalah baiknya manajemen komunikasi antara kepala ruang dengan perawat, komunikasi kepala ruang harus dilakukan dua arah serta harus terbangun komunikasi jangka panjang sehingga perawat yang ada di ruang rawat inap RSU Aro Pekalongan merasa nyaman dan aman untuk berkomunikasi selain itu baiknya komunikasi kepala ruang kepada perawat merupakan bentuk perhatian khusus yang diberikan kepala ruang untuk perawat di ruang rawat inap. ${ }^{10}$

Tabel 3 Hubungan Pengambilan Keputusan dengan Kepuasan

\begin{tabular}{|l|c|c|c|c|}
\hline \multirow{2}{*}{$\begin{array}{c}\text { Pengambilan } \\
\text { Keputusan }\end{array}$} & \multicolumn{4}{|c|}{ Kepuasan } \\
\cline { 2 - 5 } & \multicolumn{2}{|c|}{ Puas } & \multicolumn{2}{c|}{ Tidak Puas } \\
\cline { 2 - 5 } & $\mathrm{f}$ & $\%$ & $\mathrm{f}$ & $\%$ \\
\hline Baik & 12 & 37,5 & 5 & 15,6 \\
\hline Kurang & 4 & 12,5 & 11 & 34.4 \\
\hline \multicolumn{7}{|c}{$* \mathrm{p}=0,034$}
\end{tabular}

Hasil uji hubungan chi square menunjukkan terdapat hubungan antara variabel pengambilan keputusan dengan kepuasan perawat di ruang rawat inap RSU Aro Pekalongan $(\mathrm{p}<0,05)$.

Pengambilan keputusan kepala ruang berhubungan dengan kepuasan perawat di ruang rawat inap RSU Aro Pekalongan dimana pengambilan keputusan merupakan tugas utama seorang pemimpin, hasil pengambilan keputusan merupakan suatu aturan/kebijakan yang dapat dijadikan pegangan bagi bawahannya dalam berperilaku. Peran pemimpin dalam proses pengambilan keputusan adalah bersama-sama dengan bawahan melakukan pemilihan dari berbagai macam alternatif yang ada untuk menentukan tujuan yang akan dicapai dengan mempertimbangkan berbagai macam aspek yang ada. ${ }^{11}$

Hal tersebut sesuai dengan peran kepala ruang rawat inap RSU Aro Pekalongan yang selalu mengadakan pertemuan dan diskusi bersama dengan perawat di ruang rawat inap RSU Aro Pekalongan dalam menentukan kebutuhan pelayanan ruang rawat inap seperti: penentuan kebutuhan SDM, sarana prasarana, alkes serta pembuatan spo rawat inap. Pengambilan keputusan yang dilakukan kepala ruang rawat inap RSU Aro Pekalongan dengan melibatkan perawat merupakan cara efektif untuk mendapat dukungan dan komitmen perawat. Strategi kolaboratif dan parsipatif yang diambil kepala ruang dengan melibatkan perawat dalam proses pengambilan keputusan merupakan metode pemberdayaan yang dapat memuaskan keinginan dan kebutuhan perawat di ruang rawat inap RSU Aro Pekalongan. Kepuasan kerja perawat di ruang rawat inap RSU Aro Pekalongan tercapai ketika perawat tersebut diajak terlibat langsung dalam pembuatan dan pengambilan keptusan.

Penelitian ini sesuai dengan penelitian yang dilakukan oleh Wahyu Budianto tahun 2015 yang mengatakan bahwa perilaku pemimpin dalam proses pengambilan keputusan memiliki pengaruh terhadap kinerja dan kepuasan kerja anggota. Sikap positif yang terbangun terhadap suatu objek merupakan alat dalam memenuhi kepuasan atas kebutuhan.

Tabel 4 Hubungan Empati dengan Kepuasan

\begin{tabular}{rrccc}
\multicolumn{3}{c}{ Kepuasan } \\
\hline \multirow{2}{*}{ Empati } & \multicolumn{3}{c}{ Kepuasan } \\
\cline { 2 - 5 } & \multicolumn{2}{c}{ Puas } & \multicolumn{3}{c}{ Tidak Puas } \\
\cline { 2 - 5 } & $\mathrm{f}$ & $\%$ & $\mathrm{~F}$ & $\%$ \\
\hline Baik & 12 & 37,5 & 6 & 18,8 \\
\hline Kurang & 4 & 12,5 & 10 & 31,2 \\
\hline \multicolumn{2}{c}{$* 0,075$} & & &
\end{tabular}

Hasil uji hubungan chi square menunjukkan tidak terdapat hubungan antara variabel empati kepala ruang dengan kepuasan perawat di ruang rawat inap RSU Aro Pekalongan ( $p>0,05)$.

Empati kepala ruang tidak berhubungan dengan kepuasan perawat di ruang rawat inap RSU Aro Pekalongan. 
Hasil penelitian terkait variabel empati yang dilakukan terhadap perawat diruang rawat inap RSU Aro Pekalongan adalah masih terdapat $18,8 \%$ perawat yang mengatakan kepala ruang rawat inap RSU Aro Pekalongan jarang menciptakan suasana lingkungan kerja yang sehat dan menyenangkan serta masih terdapat perawat yang mempersepsikan bahwa kepala ruang jarang bersikap ramah dan jarang memperlakukan perawat sebagai teman kerja. Berdasarkan hal tersebut dapat disimpulkan bahwa masih terdapat perawat yang mempersepsikan kepala ruang rawat inap RSU Aro Pekalongan masih mempunyai empati yang kurang.

Hal ini tidak sesuai dengan pendapat Sitorus yang menyatakan bahwa keberhasilan kepala ruang bergantung pada kemampuan kepala ruang untuk dapat mempengaruhi perawat yang dipimpinnya. Salah satu kemampuan kepala ruang yang dapat mempengaruhi kepuasan bawahnnya adalah baiknya hubungan interpersonal yang ditumbuhkan oleh kepala ruang termasuk juga dalam hal ini adalah empati. $^{12}$

Penelitian ini tidak sesuai dengan pernyataan Lestari et, al bahwa empati merupakan faktor penting yang menentukan tingkat kepuasan pasien dan tidak sesuai dengan penelitian yang dilakukan olej Like J Mumu pada tahun 2015 yang mengatakan bahwa empati berhubungan dengan kepuasan pasien di Poliklinik Penyakit Dalam RSUP Prof.Dr.R.D. Kandou Manado. ${ }^{13,14}$

\section{KESIMPULAN}

Dari penelitian ini dapat disimpulkan bahwa ada pengaruh gaya kepemimpinan demikratis dengan kepuasan kerja. Hal ini dapat dilihat dari variabel gaya kepemimpinan demokratis dengan kepuasan kerja perawat di RSU Aro Pekalongan adalah variabel pendelegasian tanggung jawab $(p=0,005)$ dan variabel pengambilan keputusan kepala ruang $(\mathrm{p}=0,034)$, sedangkan variabel lain yang tidak berhubungan dengan kepuasan kerja perawat adalah variabel keaktifan kepala ruang $(p=0,077)$ dan variabel empati $(\mathrm{p}=0,075)$.

Hal tersebut sesuai dengan pendapat yang dikemukakan olej Andrew J. DuBrin dimana tujuan utama dari pendelegasian tanggung jawab adalah untuk pengalihan tanggung jawab dari seorang pemimpin kepada bawahannya sebagai sarana untuk meningkatkan produktivitas seseorang. Dengan adanya pendelegasian yang baik dari seorang pemimpin dapat mempengaruhi karyawan untuk dapat berkembang dan belajar bagaimana melaksanakan pekerjaan agar dapat lebih meningkatkan produktivitas kerjanya. ${ }^{15}$

\section{DAFTAR PUSTAKA}

1. Kleinman, Carol. The Relationship between Managerial Leadership Behaviors and Staff Nurse Retension.Journal Proquest Nursing and Allied Health Source, 82:4; 2004.

2. Clarke, Sean, P. Job Satisfaction (Survey Report), http:www.nursing 2007.com; 2007.

3. Rimbun, Lenny, R. Kepuasan Kerja Perawat di rumah sakit " $X$ " di Jakarta. Jakarta: Universitas Indonesia; 2013.

4. Wang, Shu, H, et all. Job Satisfaction off staff nurse and their perception on head hurses leadership. Journal of Public Health and Development,11:1; 2003.

5. Simamora, Raymond. Hubungan Persepsi Perawat Pelaksana terhadap Penerapan Fungsi Pengorganisasian yang Dilakukan Oleh Kepala Ruangan dengan Kinerjanya Diruang Rawat Inap RSUD Koja Jakarta Utara. 2005.

6. Nursalam. Proses dan Dokumntasi Keperawatan, Konsep dan Praktek. Jakarta: Salemba Medika; 2011.

7. Soekiman, Johanes F X. Analisis Faktor-Faktor Internal Perusahaan yang Mempengaruhi Kepuasan Kerja 
Karyawan PT. Petro Central Gresik. Jurnal Ekuitas. Desember 2005; 9(4): 585-605.

8. Herzberg, Frederick. Herzberg's Motivation-Hygiene Theory and Job Satisfaction in The Malaysian Retail Sector: The Mediating Effect Of Love Money. Sunway University Malaysia: Teck Hang Tan and Amna Waheed; 2011.

9. Librianty Nany, Rezky Dewi. Hubungan Fungsi Supervisi dan Komunikasi Kepala Ruangan dengan Kepuasan Kerja Perawat Pelaksana di Rumah Sakit Umum Daerah Rokan Hulu Tahun 2014. Jurnal Kesehatan Masyarakat Stikes Tuanku Tambusai Riau; 2014.

10. Allafchi, Nagmeh. Effect of Democratic Leadership Style on Management of Communication With Customers in Melli Banks of Hamedan. International Journal of Cultural anda Social Studies (IntJCSS). Dec 2017; 3(2).

11. Budianto, Wahyu. Kepemimpinan dalam Pengambilan Keputusan. Transformasi. 2015; 1(27): 1-47.

12. Sitorus, Ratna. Manajemen Keperawatan di Ruang Rawat. Jakarta: Sagung Seto; 2001.

13. Lestari, Sunarto, Kuntari. Analisa Faktor Tingkat Kepuasan Pasien di Rumah Sakit PKU Muhammadiyah Bantul. Jurnal Kedokteran dan Kesehatan Indonesia; 2002.

14. Mumu Like J, Kandou Grace D, Doda Diana V. Analisis Faktor-Faktor yang Berhubungan dengan Kepuasan Pasien di Poliklinik Penyakit Dalam RSUP Prof. Dr.R.D. Kandou Manado. EJournal Unsrat; 2015.

15. Dubrin, Andrew J. Essentials of Management 9th Edition: Ohio: South Westrn; 2012. 